\title{
School Counselors' Recognition of the Ultra-High Risk for Psychosis
}

\author{
Ju-Yeon Lee ${ }^{1,2}$, Young-Chul Chung ${ }^{3}$, Jae-Min Kim¹, Il-Seon Shin ${ }^{1}$, Jin-Sang Yoon ${ }^{1}$, and Sung-Wan Kim ${ }^{1,2} \bowtie$ \\ 'Department of Psychiatry, Chonnam National University Medical School, Gwangju, Republic of Korea \\ ${ }^{2}$ Gwang-ju Mental Health Commission, Gwangju, Republic of Korea \\ ${ }^{3}$ Department of Psychiatry, Chonbuk National University Medical School, Jeonju, Republic of Korea
}

The ability to identify students at ultra-high risk (UHR) for psychosis in school settings is crucial for enabling appropriate referral to a clinician and positive therapeutic results. The aim of this study was to examine school counselors' recognition of the diagnosis and appropriate treatment recommendations for students at UHR for psychosis. In total, 132 school counselors completed surveys, including questions relating to a vignette about a student at UHR for psychosis. In total, $12.4 \%$ of the sample provided the correct diagnosis, much lower than that for other schizophrenia spectrum disorders and non-psychotic disorders, including depressive disorder. Although most school counselors preferred psychiatrists as the first-line treatment for students at UHR for psychosis, counseling centers were also mentioned as potential treatment options. In terms of medication, antipsychotics were preferred over other medication classes. It is necessary to design appropriate educational and training programs for school counselors to promote identification and effective referral of those at UHR for psychosis.

Psychiatry Investig 2018;15(3):320-324

Key Words School counselor, Ultra-high risk for psychosis, Recognition, Vignette.

\section{INTRODUCTION}

The most common time of onset for psychotic disorders is adolescence and early adulthood. ${ }^{1}$ The onset of psychotic disorders is usually preceded by a prodromal period characterized by non-specific psychiatric and attenuated psychotic symptoms accompanied by functional decline. "Ultra-high risk" (UHR) for psychosis is defined by the presence of attenuated positive psychotic symptoms without full impairment of reality testing. Recently, the UHR concept was included in "attenuated psychosis syndrome" (APS), a new diagnosis contained in Section 3 of the Diagnostic and Statistical Manual of Mental Disorders, Fifth Edition (DSM-5), the section reserved for conditions requiring further research. ${ }^{3}$ Among adolescents who reported psychotic-like experiences, those of $80 \%$ remitted, and the symptoms of $20 \%$ persisted. ${ }^{4}$ The early detection and treatment of people at risk for psychosis is currently re-

Received: February 23, 2017 Revised: April 26, 2017

Accepted: June 19, 2017

$\triangle$ Correspondence: Sung-Wan Kim, MD, PhD

Department of Psychiatry, Chonnam National University Medical School, 42 Jebong-ro, Dong-gu, Gwangju 61469, Republic of Korea

Tel: +82-62-220-6148, Fax: +82-62-225-2351, E-mail: swkim@chonnam.ac.kr

(c) This is an Open Access article distributed under the terms of the Creative Commons Attribution Non-Commercial License (http://creativecommons.org/licenses/bync/4.0) which permits unrestricted non-commercial use, distribution, and reproduction in any medium, provided the original work is properly cited. garded as a promising strategy for preventing the devastating consequences of full-blown psychosis. ${ }^{5}$

As children and adolescents spend a large portion of their time at school, mental health problems are commonly identified in this setting. School-based detection of those at UHR for psychosis has the benefit of improving access to mental health treatment for students who have psychotic-like experiences. In Korea, mandatory school based mental health screening test for mental health problems of students has been conducted every year. Due to limited school mental health resources, school counselors perform non-counseling related activities beyond their training such as clinical expertise regarding to assessment and referral of clinical high risk students.

Given increasing recognition of the need to identify individuals with UHR risk status, school counselors are facing the challenge of how to understand and deal with these symptoms. Indeed, in view of the essential contribution of the identification of symptoms to the provision of effective mental health services, it is essential to recognize the potential role played by school counselors.

Thus, the current study examined how school counselors diagnose and define the appropriate treatment for those at UHR for psychosis. We assessed respondents' recognition of UHR for psychosis based their responses to a brief vignette depicting a hypothetical student reporting relevant symptoms. 


\section{METHODS}

\section{Participants}

The sample for this anonymous cross-sectional survey, which was conducted in October 2015, consisted of school counselors. In total, 132 school counselors from 125 (81.7\%) of the 153 schools and all of three Wee centers in Gwangju metropolitan city participated in the survey and completed the questionnaire. Data on sociodemographic characteristics were collected. The survey was approved by the the Chonnam National University Hospital Institutional Review Board (CNUH-2015-171).

\section{Vignette}

The vignette used in this study was developed by the corresponding author (KSW) (Table 1) based on the vignette developed by Jacobs et al. ${ }^{6}$ and the manual of Personal Assessment and Crisis Evaluation (PACE) clinic of Orygen Youth Health in Melbourne, Australia. ${ }^{7}$ The vignette described a fictional individual at UHR for psychosis according to the Comprehensive Assessment of At-Risk Mental States (CAARMS) criteria. ${ }^{89}$ The protagonist in the vignette met criteria for subthreshold non-bizarre ideation and perceptual abnormality with functional decline. She also met criteria of the DSM-5 criteria for APS. Two authors (LJY and CYC) with extensive experience in this area discussed and further revised the vignette.

First, we asked participants whether the vignette depicted a psychiatric disorder (yes/no/don't know). Participants were asked to identify the most appropriate diagnosis for the hypothetical student from a list of 10 diagnoses. We also asked participants to recommend an appropriate referral and treatment approach for the student by asking them to rate 11 treatment options on the following scale: first choice, second-or-later choice, would not recommend, and no opinion. Participants who diagnosed the protagonist with schizophrenia, delusional disorder, or at UHR for psychosis were considered the "schizophrenia spectrum disorders group," and others were considered the "non-psychotic disorders group."

\section{Statistical analyses}

Basic demographic differences among respondents according to the diagnosis chosen were analyzed using the chi-square test. The percentage of respondents choosing each answer was calculated and is presented. SPSS for Windows software (ver. 21.0; IBM Corp., Armonk, NY, USA) was used to perform the statistical tests. All statistical tests were two-tailed, and pvalues $<0.05$ were deemed to indicate statistical significance.

\section{RESULTS}

\section{Demographic characteristics of participants}

The sample consisted primarily of females (94.7\%), and there were no significant differences in the demographic characteristics of respondents according to the diagnosis they selected (Table 2).

\section{Diagnosis}

In total, 123 (94.6\%) respondents recognized that the vignette depicted someone with a mental disorder. The data regarding diagnoses are summarized in Figure 1, which shows the percentage of respondents choosing each diagnosis. The most common diagnosis was schizophrenia $(\mathrm{n}=34,28.1 \%)$, followed by delusional disorder $(n=32,26.4 \%)$, and depressive disorder $(n=23,19.0 \%)$. The diagnosis of UHR for psychosis was selected by 15 (12.4\%) subjects.

\section{Referral and treatment}

Figure 2 shows the referral recommendations according to the diagnosis chosen by the school counselors. Most participants who diagnosed the protagonist with schizophrenia spectrum disorder selected psychiatric clinics as the optimal referral. Additionally, an average of $58.1 \%$ of respondents would refer to Wee center, which is school counseling services, and an average of $37.2 \%$ would refer to a private counseling center.

Figure 3 shows treatment preferences according to the diagnosis chosen by school counselors. School counselors who diagnosed the student depicted in the vignette with schizophrenia were likely to recommend antipsychotics (35.3\%) and family therapy (35.3\%) as the first-line treatment. School coun-

Table 1. Vignette 
Table 2. Sociodemographic characteristics of school counselors according to diagnostic category endorsed

\begin{tabular}{|c|c|c|c|c|c|}
\hline \multirow[b]{2}{*}{ Characteristics } & \multirow[b]{2}{*}{$\mathrm{N}(\%)$} & \multicolumn{2}{|c|}{ Diagnostic category } & \multirow[b]{2}{*}{$\chi^{2}$} & \multirow[b]{2}{*}{$\mathrm{p}$} \\
\hline & & $\begin{array}{l}\text { Schizophrenia spectrum disorders } \\
{[\mathrm{N}=81(61.4 \%)]}\end{array}$ & $\begin{array}{c}\text { Non-psychotic disorders } \\
{[\mathrm{N}=51(38.6 \%)]}\end{array}$ & & \\
\hline Gender & & & & 0.056 & 0.553 \\
\hline Male & $7(5.3)$ & $4(57.1)$ & $3(42.9)$ & & \\
\hline Female & $125(94.7)$ & $77(61.6)$ & $48(38.4)$ & & \\
\hline Age, years & & & & 1.121 & 0.195 \\
\hline$\leq 40$ & $38(28.0)$ & $26(68.4)$ & $12(31.6)$ & & \\
\hline$>40$ & $94(72.0)$ & $55(58.5)$ & $39(41.5)$ & & \\
\hline Marital status & & & & 0.403 & 0.343 \\
\hline Married & $105(79.5)$ & $63(60.0)$ & $42(40.0)$ & & \\
\hline Not-married & $27(20.5)$ & $18(66.7)$ & $9(33.3)$ & & \\
\hline Religion & & & & 0.014 & 0.535 \\
\hline No & $37(28.0)$ & $23(62.2)$ & $14(37.8)$ & & \\
\hline Yes & $95(72.0)$ & $58(61.1)$ & 37 (38.9) & & \\
\hline School level & & & & 5.266 & 0.072 \\
\hline Elementary & $19(14.4)$ & $12(63.2)$ & $7(36.8)$ & & \\
\hline Middle & $71(53.8)$ & $48(67.6)$ & $23(32.4)$ & & \\
\hline High & $30(22.7)$ & $13(43.3)$ & $17(56.7)$ & & \\
\hline Wee center* & $12(9.1)$ & $8(66.7)$ & $4(33.3)$ & & \\
\hline Career, year & & & & 0.000 & 0.564 \\
\hline$\leq 5$ & $70(53.0)$ & $43(61.4)$ & $27(38.6)$ & & \\
\hline$>5$ & $62(47.0)$ & $38(61.3)$ & $24(38.7)$ & & \\
\hline
\end{tabular}

*Wee center is the organization's name of the office of education in Korea, which locate within each city and has been offering program and counseling services to students who need more attention in mental health problems

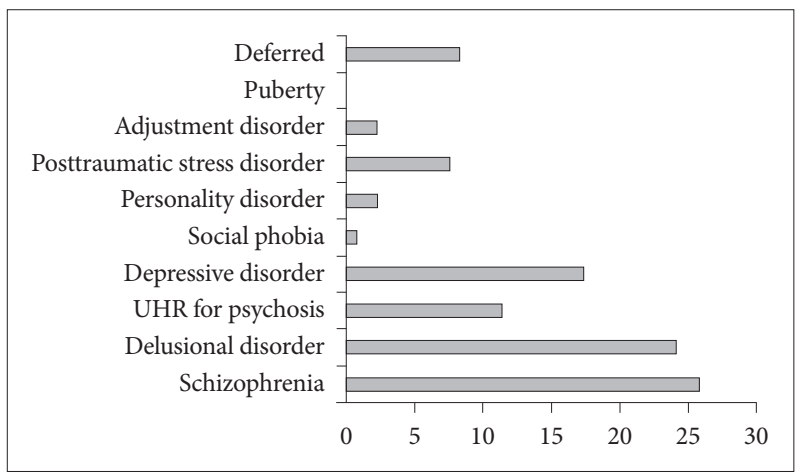

Figure 1. Diagnoses endorsed (\%). UHR: ultra-high risk.

selors who diagnosed the protagonist as being at UHR for psychosis were also likely to prefer family therapy (46.7\%). In terms of the medication options for those at UHR for psychosis, antipsychotics were the most frequently chosen.

\section{DISCUSSION}

This is the first study to explore the recognition of Korean school counselors regarding students at UHR for psychosis. Participants were presented with a vignette depicting the case

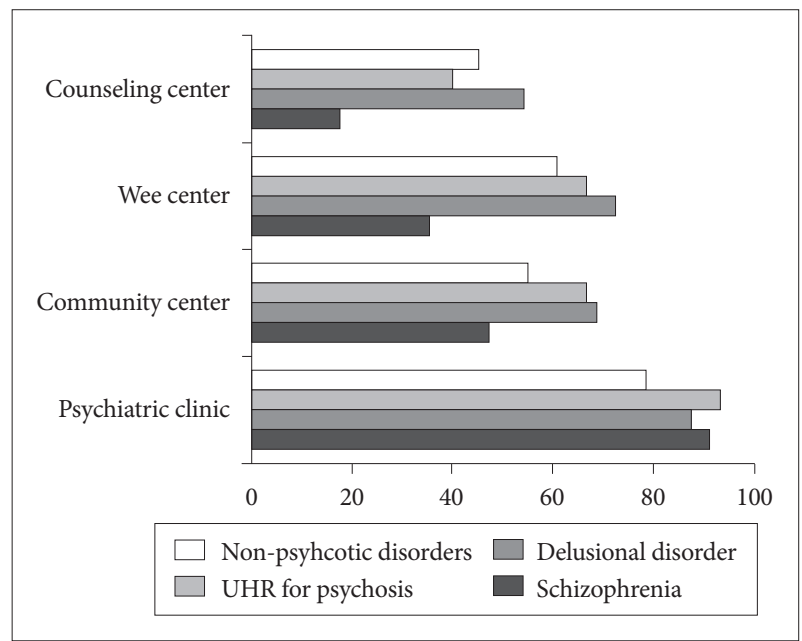

Figure 2. Referrals by diagnostic category (\%). UHR: ultra-high risk.

of a student who initially presents with recent-onset subsyndromal psychotic symptoms with functional decline. We found that most participants believed that the student was suffering from a psychiatric disorder. However, only $12.4 \%$ of the respondents correctly diagnosed her as at UHR for psychosis, whereas over half of respondents described her as suffering 


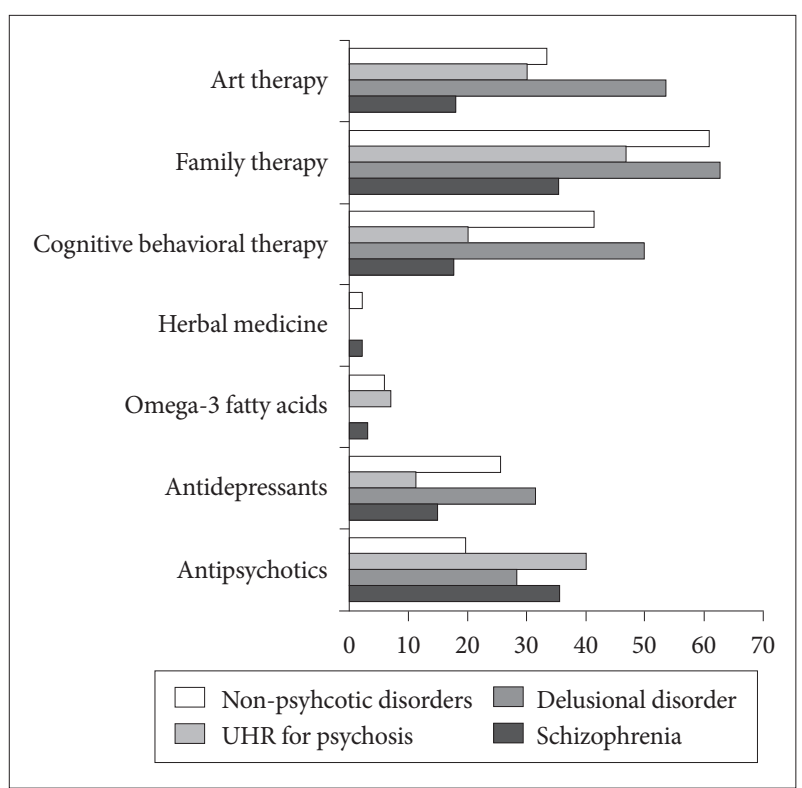

Figure 3. Treatment recommendations by diagnostic category (\%). UHR: ultra-high risk.

from a full-blown psychotic disorder. This reflects the fact that school counselors may be unfamiliar with the concept of high risk for psychosis, and lack confidence in treating this concept as a potential precursor of psychotic symptoms.

About $40 \%$ of school counselors did not consider the protagonist in the vignette to be suffering from schizophrenia spectrum disorder but, instead, believed she was dealing with a less severe condition, including depressive disorder (19.0\%). Although the vignette did not portray severe depression, many school counselors nonetheless identified the problem in question as depressive disorder, which is a common psychiatric disorder among students. While most school counselors recommended psychiatric treatment for the protagonist in the vignette, a majority also considered a counseling center, which might not offer psychiatric services and might not operate according to the medical model, as would be appropriate for the treatment of a psychotic disorder. Early detection and intervention have an important role in reducing the duration of untreated psychosis (DUP) and ameliorating the presenting symptoms of UHR subjects. ${ }^{10,11}$ However, appropriate psychiatric intervention is commonly delayed within mental health services, including school counseling systems. ${ }^{12,13}$ Therefore, early referral and the timely delivery of transfer information by school counselors may play an important role in improving the diagnostic and treatment approach of subsequent practitioners.

Our findings reflected great variability in the treatment recommendations offered for the protagonist of the vignette. In particular, school counselors who diagnosed her with schizophrenia or at UHR for psychosis recommended both anti- psychotics and family therapy. These results may be attributable to recognition on the part of school counselors that antipsychotics have been established as a standard treatment for persons with psychotic symptoms. Additionally, as school counselors are more frequently exposed to information related to familial and environmental problems, they may consider family therapy to be an important resource for treatment. Although low doses of antipsychotics appear to be effective for reducing the severity of the presenting symptoms of UHR subjects, premature recommendations for medication by school counselors may exacerbate a student's experience of being odd and stigmatized, especially if they are adolescents. ${ }^{14}$ Furthermore, there is growing evidence that psychological interventions, such as cognitive-behavioral therapy, and newly emerging treatments, such as omega- 3 fatty acids, may be effective in reducing the severity of the symptoms experienced by individuals at UHR for psychosis. ${ }^{15-17}$ These results suggest that Korean school counselors were not familiar with preventive approaches to the development of psychotic disorders or with the importance of early intervention. Thus, we should develop educational materials to raise the awareness of school-based gatekeepers of access to mental health treatment regarding psychosis prevention and help school counselors expand their knowledge about treatment options for those at UHR.

This study has several limitations. First, the use of only one vignette to assess school counselors' recognition of UHR for psychosis may have led to difficulties in distinguishing this condition from other psychotic disorders. Second, we asked only two categorical questions regarding the diagnosis of, and treatment for, individuals at UHR for psychosis; that is, we did not assess such additional factors as respondents' experiences with, goals for, and opinions regarding treatment. Future research may benefit from adding vignettes that depict different levels of psychotic symptoms and elicit more information from respondents. Moreover, as there is no "golden standard" treatment for UHR, the range of recommended treatments in our study should be tested for relevance in futures.

In conclusion, this study suggests that Korean school counselors are not sufficiently familiar with the condition known as UHR for psychosis, although they generally recognize the vignette has mental health problems and needs help. To prevent delays in the implementation of appropriate school-based interventions for attenuated psychotic symptoms, school counselors should be provided with proper education and training.

\section{Acknowledgements}

This study was supported by a grant of the Korean Mental Health Technology R\&D Project, Ministry of Health \& Welfare, Republic of Korea (HM15C1140). This research work was conducted as part of the Gwangju 
Mental Health Demonstration Project supported by Ministry of Health \& Welfare and Gwangju Metropolitan city, Republic of Korea.

\section{REFERENCES}

1. Häfner H, Riecher-Rössler A, An Der Heiden W, Maurer K, Fätkenheuer B, Löffler W. Generating and testing a causal explanation of the gender difference in age at first onset of schizophrenia. Psychol Med 1993;23:925-940.

2. Yung AR, McGorry PD. The prodromal phase of first-episode psychosis: past and current conceptualizations. Schizophr Bull 1996;22:353370.

3. American Psychiatric Association. Diagnostic and Statistical Manual of Mental Disorder, 5th ed. Arlington, VA: American Psychiatric Publishing; 2013.

4. Linscott RJ, van Os J. An updated and conservative systematic review and meta-analysis of epidemiological evidence on psychotic experiences in children and adults: on the pathway from proneness to persistence to dimensional expression across mental disorders. Psychol Med 2013;43:1133-1149.

5. Algon S, Yi J, Calkins ME, Kohler C, Borgmann-Winter KE. Evaluation and treatment of children and adolescents with psychotic symptoms. Curr Psychiatry Rep 2012;14:101-110.

6. Jacobs E, Kline E, Schiffman J. Practitioner perceptions of attenuated psychosis syndrome. Schizophr Res 2011;131:24-30.

7. Thompson AD. The PACE Clinic Manual: A Treatment Approach for Young People at Ultra High Risk of Psychosis. Melbourne: Orygen Youth Health; 2012.

8. Yung AR, Pan Yuen H, Mcgorry PD, Phillips LJ, Kelly D, Dell'Olio M, et al. Mapping the onset of psychosis: the comprehensive assessment of at-risk mental states. Aust N Z J Psychiatry 2005;39:964-971.

9. Fusar-Poli P, Cappucciati M, Rutigliano G, Lee TY, Beverly Q, Bonoldi
I, et al. Towards a standard psychometric diagnostic interview for subjects at ultra high risk of psychosis: CAARMS versus SIPS. Psychiatry J 2016;2016:7146341.

10. Ruhrmann S, Schultze-Lutter F, Klosterkötter J. Early detection and intervention in the initial prodromal phase of schizophrenia. Pharmacopsychiatry 2003;36(suppl 3):S162-S167.

11. Marshall M, Lewis S, Lockwood A, Drake R, Jones P, Croudace T. Association between duration of untreated psychosis and outcome in cohorts of first-episode patients: a systematic review. Arch Gen Psychiatry 2005;62:975-983.

12. Birchwood M, Connor C, Lester H, Patterson P, Freemantle N, Marshall $\mathrm{M}$, et al. Reducing duration of untreated psychosis: care pathways to early intervention in psychosis services. Br J Psychiatry 2013;203:5864.

13. Schimmelmann BG, Schultze-Lutter F. Early detection and intervention of psychosis in children and adolescents: urgent need for studies. Eur Child Adolesc Psychiatry 2012;21:239-241.

14. Mees L, Zdanowicz N, Reynaert C, Jacques D. Adolescents and young adults at ultrahigh risk of psychosis: detection, prediction and treatment. A review of current knowledge. Psychiatr Danub 2011;23(suppl 1):S118S122.

15. de Koning MB, Bloemen OJ, van Amelsvoort TA, Becker HE, Nieman $\mathrm{DH}$, van der Gaag M, et al. Early intervention in patients at ultra high risk of psychosis: benefits and risks. Acta Psychiatr Scand 2009;119: 426-442.

16. Amminger GP, Mechelli A, Rice S, Kim SW, Klier CM, McNamara RK, et al. Predictors of treatment response in young people at ultra-high risk for psychosis who received long-chain omega-3 fatty acids. Transl Psychiatry 2015;13:e495.

17. Ruhrmann S, Schultze-Lutter F, Klosterkötter J. Intervention in the at-risk state to prevent transition to psychosis. Curr Opin Psychiatry 2009;22: 177-183. 